\title{
Organization Postal Address
}

National Cancer Institute

\section{Source}

National Cancer Institute. Organization Postal Address. NCI Thesaurus. Code $C 93875$.

A contact point used to send physical forms of communication to the organization. 